\title{
The enemy of my enemy is still my enemy: the biological invasion and management of Gambusia in Peninsular India
}

\author{
M. Nobin Raja* and G. Ravikanth
}

Aquatic invasive species negatively impact the native aquatic communities in many parts of the world. Every nation faces the issue of introduced species, but the efforts to manage them depend on the varying capacity and willingness to manage invasions globally. Aquatic invasive species have their own set of challenges; it is crucial to understand the invasion dynamics of these species as well as their nature of interaction with humans to devise better mitigation processes. The freshwater aquatic wealth of India is seriously threatened by pollution, flow modification, overexploitation, habitat degradation and invasive alien species. India has several globally known freshwater invasive species. This article explores the invasion dynamics, potential pathways of invasion and impacts of the introduction of two of the world's top 100 invasive species, which remain relatively unknown in India: Gambusia affinis and Gambusia holbrooki. In the early 19th century, Gambusia species were introduced into Lalbagh Lake, Bengaluru, and eventually to other parts of the country. Gambusia is now widely distributed in the wild and in many Protected Areas, where it has become a threat to endangered amphibians, fishes and other aquatic invertebrates. This article explores the distribution of these Gambusia species in India and the drivers leading to their invasion. It also explains the obscure history of Gambusia invasion in India and the lack of awareness of its possible negative impacts. The importance of using molecular tools in taxonomy and their applications in invasion ecology are discussed. This study highlights the research gaps in invasion ecology of this genus in India and suggests scientific methods to manage these invasive species.

Keywords: Aquatic invasive species, biological invasion, Gambusia affinis, Gambusia holbrooki, molecular tools.

IT is widely known that invasive species often cause loss of biodiversity by leading to population declines of native species ${ }^{1}$. An invasive species can be defined as any species that has moved beyond its natural distribution range, and can reproduce and maintain its population over several generations, produce fertile offspring, often in very large numbers at considerable distances from the parent and/or site of introduction, or has the potential to spread over long distances, causing negative effects on the local biota $^{2}$. With the rapid increase in anthropogenic activity in the last few centuries, the earth's biota has been transported at a higher rate than ever before in geological history causing biological invasion ${ }^{3}$. Invasion ecology has helped us understand the dynamics of such populations and their impacts in their non-native range as well as their interaction with the native species in the newly

M. Nobin Raja and G. Ravikanth are in the Ashoka Trust for Research in Ecology and the Environment, Royal Enclave, Srirampura, Jakkur Post, Bengaluru 560 064, India; M. Nobin Raja is also with Manipal Academy of Higher Education (MAHE), Manipal 576 104, India.

*For correspondence. (e-mail: nobin.raja@atree.org) colonized environment ${ }^{1}$. Understanding the mechanisms underlying such interactions could help in minimizing the negative effects of invasive species.

Biological invasion consists of a series of stages and barriers starting from the introduction, naturalization and establishment of an alien species, to its negative impacts on the environment, society and economy of the invaded region ${ }^{4}$. An alien species can get introduced into a new environment via three different pathways ${ }^{5}$ : (a) natural spread, where the species extends its borders due to natural disasters or human-mediated large-scale disturbances which create opportunities for a dominant species to expand its range; (b) accidental introductions through activities such as trade, movement of livestock and people, and supplies during disaster management which can create pathways for alien species to move into new areas and (c) deliberate introductions, wherein a species is deliberately introduced into new localities for agriculture, aquaculture, horticulture, pet trade or for research and biocontrol purposes ${ }^{6}$. Deliberate introductions of such species for the biocontrol of another species have been of 
great concern, as they can have serious impacts on the native biodiversity. The success of invasive species has been largely attributed to propagule pressure and their escape from natural controls such as predators, parasites or competitors that would regulate their population size in their native habitats ${ }^{3}$.

There have been several instances where deliberate introductions for biocontrol have gone wrong. In 1935, invasive cane toads (Rhinella marina) were introduced to northeastern Queensland, Australia, from Hawaii to control populations of grey-backed cane beetles (Dermolepida albohirtum) and French beetle (Lepidiota frenchi). This rapidly turned into a disastrous event as cane toads became a major pest in Australia, causing negative ecological impacts on ants, snails, fishes, anurans, lizards, birds and even young crocodiles ${ }^{7}$. Another interesting case is the introduction of the Rosy wolfsnail (Euglandina rosea) in Hawaii ${ }^{8}$ to control the giant African snail (Achatina spp). In an unexpected turn of events, the wolfsnails preferentially fed upon native molluscs of Hawaii $^{8}$ and became a major pest ${ }^{9}$. Introducing an alien species for biocontrol can negatively influence the native diversity and can cause serious impact on people's livelihoods ${ }^{10}$.

Introduction of the western mosquitofish Gambusia affinis (Baird \& Girard 1853) and the eastern mosquitofish Gambusia holbrooki (Girard 1859) in freshwater ecosystems around the world has led to the widespread distribution of these species outside their native range ${ }^{11}$. $G$. affinis and G. holbrooki are freshwater fishes that were recommended for biocontrol of mosquitoes globally in malaria control programmes ${ }^{12}$. Native to USA, these fishes are now global residents. The Gambusia genus consists of 45 different species $^{13}$. Mosquitofish are now well known to cause negative ecological impact, such as the extinction of native fishes, amphibians and several other freshwater communities by outcompeting and preying on native fauna ${ }^{14}$. Gambusia species are some of the most widespread freshwater fishes as they are hardy with high tolerance towards changing environmental conditions $^{12}$. Gambusia are small-sized $(4-7 \mathrm{~cm})$, diurnal, viviparous surface-feeder fish that feed on copepods, zooplankton, Cladocera, surface insects, dipteran larvae, coleoptera, small benthos, molluscs, vegetation, algae, frog tadpoles and fish eggs ${ }^{12,15,16}$.

The life-history traits of Gambusia make them wellsuited to establishing self-sustaining populations in new environments. Male Gambusia reach sexual maturity in a month and female in six weeks ${ }^{16}$. The gestation period lasts for 24 days. The brood size varies among females with different age classes. Female Gambusia can retain sperm from the male and can impregnate themselves at different times, thus having the ability to colonize new locations $^{12}$. In addition, Gambusia can adapt to new environments and climate quite effectively ${ }^{12}$, and can be opportunistic at individual as well at population level, where they can attain early maturity, have a long reproductive season, switch to ovoviviparity and have multiple brood sessions with a high survival rate ${ }^{14}$. Due to such adaptability, they have been successful across various freshwater ecosystems around the world.

\section{The origins of Gambusia in India}

The global journey of Gambusia started in the early 20th century, when they were first introduced in the vicinity of Camden, England in 1905 (ref. 16). In 1921, G. affinis was reported to have been introduced in Italy and other parts of Europe ${ }^{17}$. However, it is not clear as to when it was introduced to India. From the available literature, there seems to be a major contradiction with respect to the species introduced and the time of introduction. G. affinis appears to have been introduced in India in 1914 from Italy and in 1930 from Siam ${ }^{18}$. However, there are also contrary reports of this species being introduced from Italy in 1928 , by B. A. Rao, to control malarial mosquitoes as a part of the Urban Malaria Scheme (UMS) and the National Malaria Eradication Programme $(\text { NMEP })^{16,19}$

Adding to the confusion, a large-scale study only showed occurrences of G. holbrooki in Europe ${ }^{20}$. Pyke ${ }^{12}$ has mentioned that the chance of two Gambusia species coexisting in the same water body is rare due to interspecific competition. In India, it is not clear which of the two species was introduced, as there has been no systematic molecular taxonomy work.

Various Government and private institutions in India stock Gambusia in their local waterbodies to fight malaria. The Indian Council of Medical Research (ICMR), New Delhi, National Institute of Malaria Research (NIMR), New Delhi, municipal corporations; district administrations; fisheries departments; district health departments; tribal development agencies; local aquaculturists and the public have all played a major role in introducing mosquitofish (see Supplementary Material 1). Gambusia and other guppy fishes were successfully introduced by Government institutions in various landscapes in Assam, Gujarat, Karnataka, Maharashtra, Rajasthan, Tamil Nadu and Uttar Pradesh ${ }^{21-23}$.

The UMS uses Gambusia and guppy (Poecilia reticulata) for its mosquito control programmes. Using larvivorous fish has been 'an important step' in the Enhanced Malaria Control Project (EMCP) and the Malaria Action Plan ${ }^{24}$. ICMR has even introduced Gambusia in the Nicobar Islands ${ }^{25,26}$ which are known to be a gold mine of endemic flora and fauna in India. According to the Island Susceptibility Hypothesis, islands are more susceptible to biological invasion than are continents ${ }^{27}$. It has been stated in the ICMR Annual Report 2003-04 that several $G$. affinis hatcheries were established and introduced into the creeks in the Nicobar Islands. 
In India, Gambusia spp. have been surviving for almost a century across various landscapes and seasons ${ }^{16}$. According to the unified framework of biological invasion ${ }^{28}$, Gambusia can be considered as a full-fledged invasive species. Unintentional contamination of Gambusia in the aquaculture trade is possible as juvenile Gambusia strongly resemble other ornamentally important fishes of the family Poecilidae. Anthropogenic activities along with natural dispersal are the main reasons for the invasion success of the species in countries outside their home range ${ }^{12}$. However, we did not come across enough evidence in India to support natural dispersal due to a lack of research in this area.

\section{Gambusia: Are they effective in mosquito control?}

Early 19th century experiments to evaluate the larvicidal efficiency of Gambusia were subjective with small sample sizes and observational experiments showing a drastic reduction in mosquito larvae in the presence of mosquitofish $^{12}$. Conversely, some studies reported that Gambusia are ineffective as a larvicide ${ }^{29}$. In fact, Pyke ${ }^{12}$ reported that Gambusia have resulted in increased population of mosquito larvae, as they prey on other larvivorous predators. Multiple studies have reported that although Gambusia are quite effective in maintaining low larval densities, they can never succeed in completely replacing rapidacting chemicals ${ }^{30}$. Guppies also have been introduced into ponds to control mosquito larvae population, but seem less efficient than Gambusia and have poor survival rates $^{31}$. However, few studies show that guppies have better efficiency as a larvicide than Gambusia ${ }^{32}$. Despite conflicting data, however, it is generally agreed upon that the larvicidal potential of the so-called G. affinis in India is considerably higher-than that of certain native fishes ${ }^{33}$.

Ghosh et al. ${ }^{19}$ reported significant reduction in malaria cases in districts of Karnataka where Gambusia and Poecilia were introduced and provided evidence that Gambusia function effectively in open waters such as streams. However, Reddy and Pandian ${ }^{34}$ showed that running waters affect the predatory efficacy of mosquitofish. In streams or ponds with agricultural run-off, Gambusia may not perform well due to elevated pesticide levels. $G$. affinis is highly vulnerable to insecticides such as profenofos and chlorpyrifos ${ }^{35-37}$. The larvicidal efficiency of Gambusia has also been shown to decline in the presence of thick vegetation ${ }^{38}$.

As discussed above, studies have not necessarily been conclusive about the effectiveness of Gambusia as a viable mosquito control. G. holbrooki also has been suggested to be ineffective for mosquito control ${ }^{39,40}$. This species feeds mostly on zooplankton, insects and zoobenthos, and mosquito larvae are negligible in its $\operatorname{diet}^{39}$. Mass reduction of zooplanktons further leads to algal bloom, thus reducing the water quality ${ }^{41}$. In fact, G. affinis faces heavy mortality when it feeds only on mosquito larvae and in order to survive, requires a mixed diet.

\section{Threats of Gambusia}

Seven decades after the first introduction outside its native environment, the negative impacts of Gambusia on native biodiversity are becoming clear ${ }^{12}$. Several experimental studies showed a reduction in rotifers, crustaceans, backswimmers, water beetles and odonate larvae in the presence of Gambusia. The negative impacts of $G$. holbrooki on native species include competition, predation and aggressive interactions which can lead to trophic cascades in the invaded ecosystem ${ }^{41,42}$. Gambusia are also known to devour amphibian tadpoles. They have been shown to feed on Microhyla tadpoles and can significantly reduce the tadpole density ${ }^{43-45}$. Tadpoles of bullfrog (Lithobates catesbeianus) and American toad (Bufo americanus) often fail to recognize the presence of alien predators like G. affinis $^{46}$.

In India, there have been few studies on the interactions of Gambusia with the native freshwater communities. In fact, the major focus of prior research has been to evaluate Gambusia as an effective player in mosquito control (Figure 1). Only few studies have evaluated the potential threats from frequent introductions of Gambusia into new ecosystems. In Pune, the native population of striped panchax (Aplocheilus lineatus) was affected by mosquitofish $^{47}$. Gambusia species are more resistant to pollution compared to other native fishes, thus outcompeting the latter ${ }^{48,49}$. Increase in Gambusia population

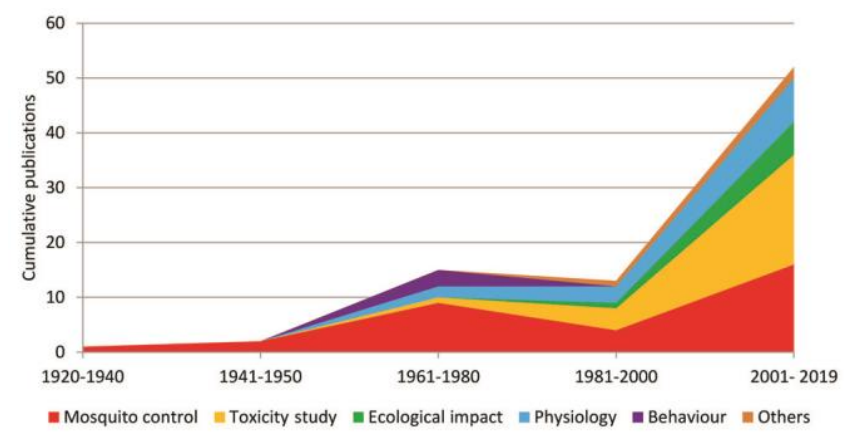

Figure 1. Number of publications with respect to subject area from 1920 to 2019. The term 'Gambusia India' was searched in Google. The 500 foremost search results were accessed, and only the appropriate publications $(n=83)$ were considered and separated based on five major subject areas (mosquito control, toxicity study, ecological impacts, physiology, others (including studies on reproductive biology, infection and survival)). (We recorded the impacts of these two species on local habitats on the basis of literature review. We collated 500 articles based on the purpose of the study, collecting a total of 83 reports focusing on the genus in India. The purpose of these studies was categorized into mosquito control, toxicity study, ecological impacts, physiological studies, and others (including studies on reproductive biology, infection and survival). Using these data, we plotted a graph with time of publication as the base (see Supplementary Material 2). 
correlates with a decline in other fishes, as they might compete for common resources ${ }^{12,50}$. Gambusia express dominant behaviour such as chasing other fishes and finnipping ${ }^{42}$. Injured native fishes are prone to bacterial infections and may eventually die ${ }^{50}$. Additionally, Gambusia feed on zooplankton and aquatic insects, which may increase the phytoplankton population ${ }^{12}$. Researchers suggested eradicating $G$. holbrooki from Nainital Lake, as it was found to alter the planktonic community ${ }^{51}$. Apart from affecting aquatic ecology, there is a possibility of Gambusia acting as a vector for diseases ${ }^{12,52}$. They may also carry alien parasites that may infect native species ${ }^{41}$.

G. affinis and $G$. holbrooki have now been identified as invasive species in many countries across six continents, except Antarctica ${ }^{12}$. Gambusia have been identified as an impending threat to several freshwater fishes of Australia ${ }^{41}$. G. holbrooki was introduced into Australia via Italy in 1925 as a mosquito control agent. It is now known to alter the existence and richness of most wetland species ${ }^{53}$. After their introduction, Gambusia started competing and negatively impacted several fishes belonging to the families Pseudomugilinae, Gobiidae, Terapontidae, Percichthyidae, Antherinidae and Ambassidae. Gambusia are also reported to prey upon certain native fishes of Australia, such as rainbowfish of the Melanotaeniidae family, black mudfish (Neochanna diversus), purple-spotted gudgeon (Mogurnda adspersa), native galaxia (Galaxias gracilis), garnet minnow (Aphyocypris lini) and Japanese rice fish (Oryzias latipes) $)^{44,54}$. Tadpoles of several native Australian frogs were also impacted due to the presence of Gambusia. Several amphibian species belonging to the families Limnodynastidae, Pleodryadidae, Rhacophoridae, etc. were under threat ${ }^{44,54}$. As Gambusia are a threat to biodiversity, the afflicted countries are trying to eradicate them from the ecosystem.

\section{Proposed management of invasive Gambusia}

\section{Identification of the invasive species}

Though the available records mention that $G$. affinis was introduced in India in 1928 from Italy, field assessments have found $G$. holbrooki in local water bodies ${ }^{16}$. Thus, it is unclear as to which of the two species was introduced in India. A large-scale molecular taxonomic study from Europe showed only the presence of G. holbrooki ${ }^{55}$. In India, researchers have described the presence of both $G$. affinis and $G$. holbrooki. Since both species have very little phenotypic variation, it is hard to distinguish them morphologically. We have collected Gambusia samples from creeks in Tura (Meghalaya), Chennai (Tamil Nadu), Dharwad as well as from Lalbagh, Bengaluru (Karnataka), where they were reportedly first introduced (see Supplementary Material 3) (Figure 2). Using the identification guide devised by Jayaram ${ }^{56}$, we morphologically identi- fied the sampled fish as Gambusia species. DNA was isolated from fish tissue, and the cytb gene was amplified and sequenced (by Eurofins Genomics India Pvt Ltd, Bengaluru $)^{55}$. In MEGA X, the sequences were aligned using ClustalW and a cladogram was constructed using maximum likelihood method with 1000 bootstrap replicates. Our preliminary analysis clearly indicated only the presence of $G$. holbrooki in the sampling sites across India (Figure 3). This is an important finding given that Gambusia has been used as a model organism in various toxicology and infectious disease studies in India ${ }^{52}$. The pre-existing official documents of malarial control departments and research articles, including taxonomic descriptions claiming the species is G. affinis need to be revised. Our molecular study also found the presence of only G. holbrooki from Lalbagh Lake in Bengaluru, which was supposed to be the first introduced population of Gambusia in India. However, the possibility of separate introduction of $G$. affinis in India cannot be ruled out, unless systematic sampling and identification are done throughout the country.

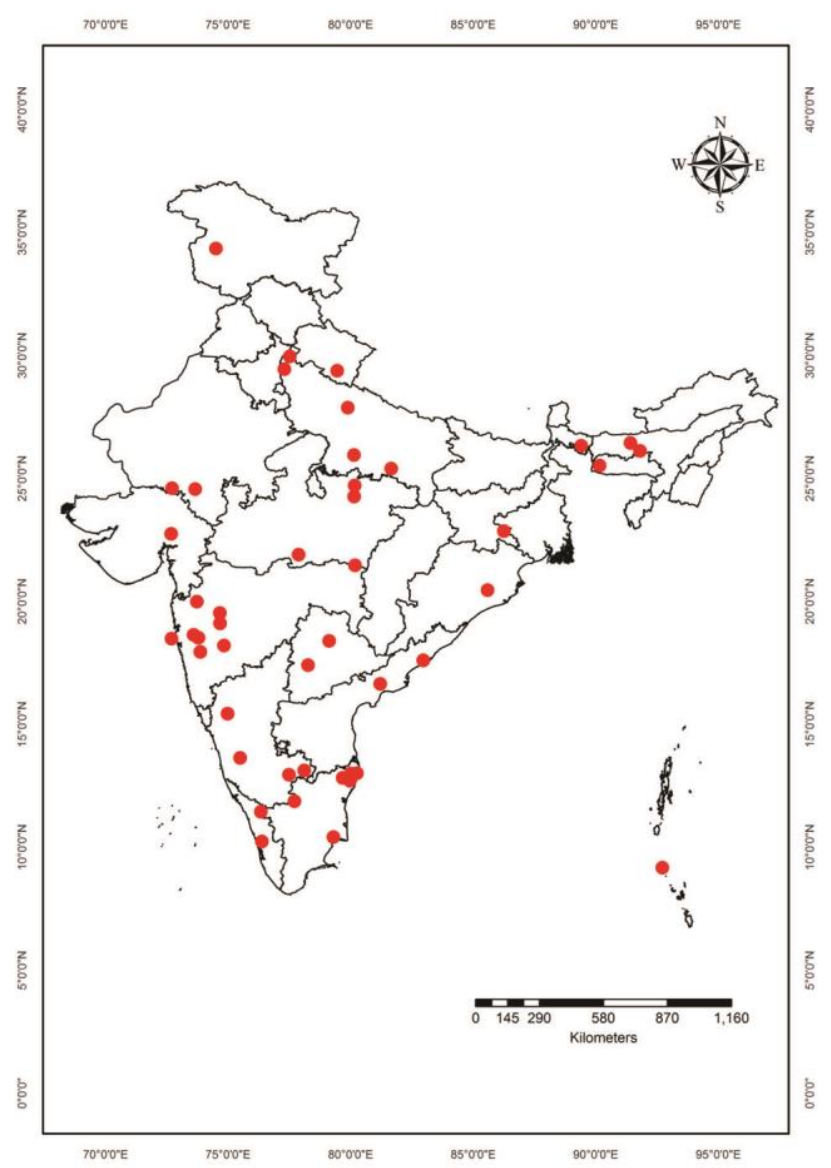

Figure 2. Current distribution of Gambusia in India based on the literature (see Annexure 2 for details). (We went through sample collection details of the reviewed articles. Field-visit data points of Gambusia were also included in this study. While we reviewed news articles and on-line media, we excluded these data as they were not scientifically confirmed. We used a larger pool of data points (45 points) and structured methodologies to update a previous map of Gambusia in India ${ }^{16}$.) 


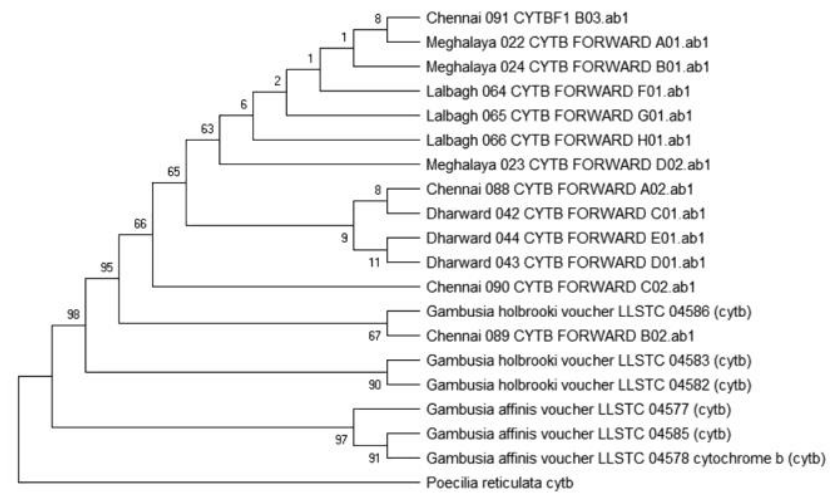

Figure 3. Simple cladogram representing the genetic relatedness of Gambusia species based on partial Cytb sequences.

\section{Genetic reconstruction of invasion history}

Understanding the invasion history of a species plays a major role in developing strategies and policy measures to eradicate or to control biological invasions. Studying invasion history provides information on the origin, invasion route and the number of introductions. There are direct and indirect methods available to reconstruct a species invasion route ${ }^{57}$. While direct methods rely on historical records and notes, and/or interviews with stakeholders or key informants ${ }^{58}$, indirect methods rely on molecular-based comparisons between native and introduced populations of the species ${ }^{59-61}$. The invasion history of the American bullfrog in Montana was assessed using the genetic differences between native and invaded populations ${ }^{62}$. The study found a broad genetic variability in the population. Based on these studies, the authors suggested legislative action to prevent further introduction, and emphasized the importance of recreating genetic history and its significance in management strategies. Comparing the haplotypic diversity and phylogeographic surveys of an introduced species within and between countries can shed light on species diversity, founding populations and their origin. With this information, the type of vectors, the route of invasion and the number of introductions can be speculated ${ }^{57}$.

Thus rebuilding the invasion history of Gambusia is important in India, especially when there is confusion with respect to the origin of source population and the species identity. While the existing literature suggests that the ongoing introductions are from a single source, there is a possibility that multiple introductions might have occurred in the past.

\section{Risk assessment}

Risk assessment is a series of methodologies to measure the potential impacts of non-native species prior to their introduction and their likelihood of establishment in the non-native environment ${ }^{63}$. Using niche modelling tools and molecular genetics can help assess the risk of introducing a species. Species distribution modelling (SDM) is widely used in invasion ecology to assess the habitat suitability of invasive species in the non-native environment ${ }^{64}$. Using suitable variables, the probable niche shifts of invasive species under future climate change scenarios could also be predicted ${ }^{64}$. Employing genomic tools such as metabarcoding for analysing the gut content of invasive fishes can provide information on their feeding behaviour. Following the modern invasion ecology framework, the Environmental Impact Classification for Alien Taxa (EICAT), alien species can be categorized into various subgroups ranging from minimal to major concern. This will help in the management of invasive species. There are only limited studies that have assessed the impacts of Gambusia in freshwater ecosystems (Figure 1). It is important that species-specific risk assessments are done at a wider scale across different habitats before Gambusia spreads across India's freshwater ecosystems.

Towards this end, we have carried out an extensive literature survey using Google Scholar to collate scientific articles published on Gambusia spp. (Figure 1) between 1920 and 2019. We used the search terms 'Gambusia + mosquito fish + India' to narrow down the results. We manually filtered the initial 500 results and collected information regarding sampling sites. Additionally, we included first-hand field-visit data points from different parts of the country to collect Gambusia specimens. The previous map of the spread of Gambusia did not explain the methods of collection and utilized 15 data points ${ }^{16}$. Our updated map follows a structured methodology and has more than 45 data points, adding to its accuracy. Updated range and risk maps for invasive species can help managers target susceptible or infected areas, and focus their resources towards monitoring and addressing the spread of Gambusia in those regions.

\section{Monitoring}

Early detection of invasive species and monitoring the potential spread to new areas are essential steps to effectively plan management strategies. Compared to a terrestrial set-up, detection and monitoring becomes a complicated process in aquatic ecosystems ${ }^{14}$. Recent advancements in eDNA-based approaches could help in monitoring the population spread as well as their densities in water bodies ${ }^{65,66}$. Gambusia can survive in a wide range of freshwater habitats and unless periodic monitoring is carried out, the species could become a major threat to other aquatic fauna ${ }^{12}$. Periodic monitoring should be carried out in the location where the fish has been introduced and also in adjacent freshwater ecosystems. 
In Australia, Gambusia have escaped into the wild streams causing serious impact ${ }^{41}$. This situation can be avoided in India by periodic monitoring. Such large-scale monitoring can be efficiently carried out using citizen science approach ${ }^{67}$, though this approach for the identification of cryptic species does come with its own challenges. However, using an effective filtering process and obtaining large-scale data could help resolve this issue ${ }^{68}$.

\section{Policy-level changes}

Gambusia have been recognized as one of the worst invasive species by the $\mathrm{IUCN}^{69}$. G. holbrooki is listed under the Invasive Alien Species Act of $\operatorname{Japan}^{70}$. G. affinis is regulated as a major invasive alien species in China ${ }^{55}$. In Australia, Gambusia are listed under the Biosecurity Act of 2014. In India, G. affinis and G. holbrooki have already been listed as invasive species by the National Biodiversity Authority ${ }^{71}$. Based on the existing data, one possible assumption is that the biological invasion of Gambusia has reached the final stage. In the unified framework the final stage, viz. 'symbol E', denotes fully invasive species $^{28}$. Gambusia are now an invasive species, with the population surviving and reproducing in various habitats across India. Unfortunately, lack of coordination between various Government institutions has resulted in Gambusia still being widely introduced into water bodies ${ }^{72,73}$. Stricter policies and enforcement are required to avoid subsequent introductions and to manage the resultant impact of Gambusia in our fragile aquatic ecosystems. Detailed studies on these species should culminate in developing robust policy measures to monitor and, if needed, in the eradication and prevention of possible spread to other water bodies.

The World Health Organization, Geneva, has stopped recommending Gambusia as a mosquito control agent nearly four decades ago ${ }^{41}$. However, in India, both Government and nongovernmental agencies alike continue to introduce the species for mosquito control. Each year, numerous species of fish are being described by ichthyologists all over the world, including India ${ }^{74}$. It is highly likely that invasive fishes like Gambusia can cause several silent extinctions of native species. In New South Wales, Australia, under the Threatened Species Conservation Act (1995), Gambusia are listed as a key threatening species. The same law also urges landowners to avoid additional spread of the fish ${ }^{41}$. India must take a strong stand against further introductions and limit the spread of Gambusia in the country in order to preserve our inherent aquatic biodiversity and native species health.

\section{Conclusion}

Gambusia is now widespread across India. Despite being listed as an invasive species by the National Biodiversity
Authority (NBA) and lack of conclusive studies on its effectiveness in mosquito control, it continues to be introduced in Indian water bodies. It is critical that further introductions are avoided and existing sites of introduction are actively monitored to limit the negative impacts of this fish on native biodiversity. Efforts should also be made to eradicate this species from freshwater ecosystems in India.

1. Vaz, A. S., Kueffer, C., Kull, C. A., Richardson, D. M., Schindler, S. and Jesu, A., The progress of interdisciplinarity in invasion science. Ambio, 2017, 46, 428-442.

2. Hui, C. and Richardson, D. M., Invasion Dynamics, Oxford University Press, Oxford, England, 2017.

3. Banks, N. C., Paini, D. R., Bayliss, K. L. and Hodda, M., The role of global trade and transport network topology in the human-mediated dispersal of alien species. Ecol. Lett., 2015, 18, 188-199.

4. Clout, M. N. and Williams, P. A., Invasive Species Management: A Handbook of Techniques, Oxford University Press, 2009.

5. Hulme, P. E. et al., Grasping at the routes of biological invasions: a framework for integrating pathways into policy. J. Appl. Ecol. 2008, 45, 403-414.

6. Pimentel, D., Biological Invasions: Economic and Environmental Costs of Alien Plant, Animal and Microbe Species, CRC Press, Boca Raton, USA, 2002

7. Shine, R., The ecological impact of invasive cane toads (Bufo marinus) in Australia. Q. Rev. Biol., 2010, 85, 253-291.

8. Kinzie, R. A., Predation by the introduced carnivorous snail $E u$ glandina rosea (Ferussac) on endemic aquatic lymnaeid snails in Hawaii. Biol. Conserv., 1992, 60, 149-155.

9. Griffiths, O., Cook, A. and Wells, S. M., The diet of the introduced carnivorous snail Euglandina rosea in Mauritius and its implications for threatened island gastropod faunas. J. Zool., 1993, 229, 79-89.

10. Macdonald, J. and Tonkin, Z., A review of the impact of eastern Gambusia on native fishes of the Murray-Darling Basin. MurrayDarling Basin Authority Publication, Canberra, 2008.

11. Rehage, J. S. and Sih, A., Dispersal behavior, boldness, and the link to invasiveness: a comparison of four Gambusia species. Biol. Invasions, 2004, 6, 379-391.

12. Pyke, G. H., Plague minnow or mosquito fish? A review of the biology and impacts of introduced Gambusia species. Annu. Rev. Ecol. Evol. Syst., 2008, 39, 171-191.

13. https://www.fishbase.in/identification/SpeciesList.php?genus=Gambusia (accessed on 10 May 2019).

14. Ruiz-Navarro, A., Verdiell-Cubedo, D., Torralva, M. and OlivaPaterna, F. J., Removal control of the highly invasive fish Gambusia holbrooki and effects on its population biology: learning by doing. Wildl. Res., 2013, 40, 82-89.

15. Specziár, A., Life history pattern and feeding ecology of the introduced eastern mosquitofish, Gambusia holbrooki, in a thermal spa under temperate climate, of Lake Hévíz, Hungary. Hydrobiologia, 2004, 522, 249-260.

16. Singh, N. and Gupta, P. K., Gambusia holbrooki: a case study in India with special reference to Lake Nainital. Int. J. Fish. Aquacult., 2016, 6, 33-48.

17. Krumholz, L. A., Reproduction in the western mosquitofish, Gambusia affinis affinis (Baird \& Girard), and its use in mosquito control. Ecol. Monogr., 1948, 18, 1-43.

18. Krishnaja, A. P. and Rege, M. S., A cytogenetic study on the Gambusia affinis population from India. Cytologia, 1983, 48, 47-49.

19. Ghosh, S. K., Tiwari, S. and Ojha, V. P., A renewed way of malaria control in Karnataka, South India. Front. Physiol., 2012, 3, 194. 
20. Sanz, N., Araguas, R. M., Vidal, O., Diez-del-Molino, D., Fernández-Cebrián, R. and García-Marín, J. L., Genetic characterization of the invasive mosquitofish (Gambusia spp.) introduced to Europe: population structure and colonization routes. Biol. Invasions, 2013, 15, 2333-2346.

21. ICMR, Annual Report, 2011-2012 and 2013-2014, Indian Council of Medical Research, New Delhi; https://www.icmr.nic.in/icmrannual-reports (accessed on 10 July 2019).

22. ICMR, Bulletin, Indian Council of Medical Research, New Delhi, January-July 2016, vol. 46, pp. 1-6; https://www.icmr.nic.in/ icmr-bulletin (accessed on 10 November 2019).

23. National Institute of Malaria Research, New Delhi, Annual Report, 2008-2009, 2009-2010, 2012-2013, 2013-2014, 2014-2015; http://back.nimr.org.in/annual-report.html (accessed on 10 October 2019)

24. ICMR, Bulletin, Indian Council of Medical Research, New Delhi, January-July 2003, vol. 33, pp. 1-7; https://www.icmr.nic.in/ icmr-bulletin (accessed on 10 August 2019).

25. Kiruba-Sankar, R., Raj, J. P., Saravanan, K., Kumar, K. L., Angel, J. R. J., Velmurugan, A. and Roy, S. D., Invasive species in freshwater ecosystems - threats to ecosystem services. In Biodiversity and Climate Change Adaptation in Tropical Islands, Academic Press, 2018, pp. 257-296.

26. Khan, Z. A. and Sunish, I. P., Tribal community visit to malariaendemic areas can pose risk to Car Nicobar Island: deterrent for malaria elimination. Int. J. Travel Med. Global Health, 2019, 7, 33-37.

27. Jeschke, J. M., Aparicio, L. G., Haider, S., Heger, T., Lortie, C. J., Pyšek, P. and Strayer, D. L., Support for major hypotheses in invasion biology is uneven and declining. NeoBiota, 2012, 20, 1-20.

28. Blackburn, T. M. et al., A proposed unified framework for biological invasions. Trends Ecol. Evol., 2011, 26, 333-339.

29. Lloyd, L., An alternative to insect control by 'mosquitofish', Gambusia affinis. Arbovirus Res. Aust., 1986, 1986, 156-163.

30. Sitaraman, N. L., Karim, M. A. and Reddy, G. V., Observations on the use of Gambusia affinis Holbrooki to control A. stephensi breeding in wells. Results of two years' study in Greater Hyderabad City - India. Indian J. Med. Res., 1975, 63, 1509-1516.

31. Sitaraman, N. L., Mahadevan, S. and Swamidas, S., Biological control of A. stephensi larvae in wells by Poecilia reticulatus in Greater Hyderabad City, India. J. Infect. Dis., 1976, 8, 315-319.

32. Ghosh, S. K. et al., Comparative efficacy of two poeciliid fish in indoor cement tanks against chikungunya vector Aedes aegypti in villages in Karnataka, India. BMC Public Health, 2011, 11, 599.

33. Bano, F. and Serajuddin, M., Comparative study of Larvicidal efficacy of four indigenous fish with an exotic top water minnow, Gambusia affinis. J. Ecophysiol. Occup. Health, 2017, 16, 7-12.

34. Reddy, S. R. and Pandian, T. J., Effect of running water on the predatory efficiency of the larvivorous fish Gambusia affinis. Oecologia, 1974, 16, 253-256.

35. Rao, J. V., Begum, G., Pallela, R., Usman, P. and Rao, R., Changes in behavior and brain acetylcholinesterase activity in mosquito fish, Gambusia affinis in response to the sub-lethal exposure to chlorpyrifos. Int. J. Environ. Res. Public Health, 2005, 2, 478-483.

36. Rao, J. V., Begum, G., Jakka, N. M., Srikanth, K. and Nageswara Rao, R., Sublethal effects of profenofos on locomotor behavior and gill architecture of the mosquito fish, Gambusia affinis. Drug Chem. Toxicol., 2006, 29, 255-267.

37. Kavitha, P. and Rao, J. V., Toxic effects of chlorpyrifos on antioxidant enzymes and target enzyme acetylcholinesterase interaction in mosquito fish, Gambusia affinis. Environ. Toxicol. Pharmacol., 2008, 26, 192-198.

38. Willems, K. J., Webb, C. E. and Russell, R. C., A comparison of mosquito predation by the fish Pseudomugil signifier (Kner) and Gambusia holbrooki (Girard) in laboratory trials. J. Vector Ecol., 2005, 30, 87.
39. Singh, N. and Gupta, P. K., Food and feeding habits of an introduced mosquitofish, Gambusia holbrooki (Girard) (Poeciliidae) in a subtropical lake, Lake Nainital, India. Asian Fish. Sci., 2010, 23, $355-366$.

40. Gkenas, C., Oikonomou, A., Economou, A., Kiosse, F. and Leonardos, I., Life history pattern and feeding habits of the invasive mosquitofish, Gambusia holbrooki, in Lake Pamvotis (NW Greece). J. Biol. Res., 2012, 17, 121.

41. White, A. and Pyke, G., World War II and the rise of the plague minnow Gambusia holbrooki (Girard, 1859) in Australia. Aust. Zool., 2011, 35, 1024-1032.

42. Rowe, D. K., Moore, A., Giorgetti, A., Maclean, C., Grace, P., Wadhwa, S. and Cooke, J., Review of the impacts of Gambusia, redfin perch, tench, roach, yellowfin goby and streaked goby in Australia. Draft report prepared for the Australian Government Department of the Environment, Water, Heritage and the Arts, Canberra, Australia, 2008

43. Ghate, H. V. and Padhye, A. D., Predation of Microhyla tadpoles by Gambusia. J. Bombay Nat. Hist. Soc., 1988, 85, 200-201.

44. Gillespie, G. and Hero, J. M., Potential impacts of introduced fish and fish translocations on Australian amphibians - declines and disappearances of Australian frogs. Environment Australia, Canberra, Australia, 1999, pp. 131-144.

45. Reynolds, S. J., Impact of the introduced poeciliid Gambusia holbrooki on amphibians in southwestern Australia. Copeia, 2009, 2009, 296-302.

46. Smith, G. R., Boyd, A., Dayer, C. B. and Winter, K. E., Behavioral responses of American toad and bullfrog tadpoles to the presence of cues from the invasive fish, Gambusia affinis. Biol. Invasions, 2008, 10, 743-748.

47. Knight, J. D. M., Invasive ornamental fish: a potential threat to aquatic biodiversity in peninsular India. J. Threat. Taxa, 2010, 2, 700-704.

48. Wagh, G. K. and Ghate, H. V., Freshwater fish fauna of the rivers Mula and Mutha, Pune, Maharashtra. Zoos Print J., 2003, 18, 977-981.

49. Kharat, S., Dahanukar, N., Raut, R. and Mahabaleshwarkar, M. Long-term changes in freshwater fish species composition in north Western Ghats, Pune district. Curr. Sci., 2003, 84, 816-820.

50. Raghavan, R., Prasad, G., Anvar-Ali, P. H. and Pereira, B., Exotic fish species in a global biodiversity hotspot: observations from River Chalakudy, part of Western Ghats, Kerala, India. Biol. Invasions, 2008, 10, 37-40.

51. Singh, N., In vivo studies on the effect of Gambusia holbrooki on planktonic community. Int. J. Fish. Aquacult. Sci., 2013, 3, 99111.

52. Praveenraj, J., Praveena, P. E., Bhuvaneswari, T., Krishnan, A. N. and Jithendran, K. P., Experimental infection of Betanoda virus in freshwater fish Gambusia affinis (Baird and Girard, 1853)-a potential infection model for viral encephalopathy and retinopathy. Aquacult. Int., 2018, 26, 617-627.

53. Macdonald, J. I., Tonkin, Z. D., Ramsey, D. S., Kaus, A. K., King, A. K. and Crook, D. A., Do invasive eastern Gambusia (Gambusia holbrooki) shape wetland fish assemblage structure in southeastern Australia? Mar. Freshw. Res., 2012, 63, 659-671.

54. Yan, X., Zhenyu, L., Gregg, W. P. and Dianmo, L., Invasive species in China - an overview. Biodivers. Conserv., 2001, 10, 1317-1341.

55. Vidal, O., García-Berthou, E., Tedesco, P. A. and García-Marín, J. L., Origin and genetic diversity of mosquitofish (Gambusia holbrooki) introduced to Europe. Biol. Invasions, 2010, 12, 841851.

56. Jayaram, K. C., The Freshwater Fishes of the Indian Region, Second Edition, Narendra Publishing House, Delhi, 2010.

57. Estoup, A. and Guillemaud, T., Reconstructing routes of invasion using genetic data: why, how and so what? Mol. Ecol., 2010, 19, 4113-4130. 
58. Mohanty, N. P. and Measey, J., Reconstructing biological invasions using public surveys: a new approach to retrospectively assess spatio-temporal changes in invasive spread. Biol. Invasions, 2019, 21, 467-480.

59. Ciosi, M., Miller, N. J., Kim, K. S., Giordano, R., Estoup, A. and Guillemaud, T., Invasion of Europe by the western corn rootworm, Diabrotica virgifera virgifera: multiple transatlantic introductions with various reductions of genetic diversity. Mol. Ecol., 2008, 17, 3614-3627.

60. Facon, B., Pointier, J. P., Glaubrecht, M., Poux, C., Jarne, P. and David, P., A molecular phylogeography approach to biological invasions of the New World by parthenogenetic thiarid snails. Mol. Ecol., 2003, 12, 3027-3039.

61. Lindholm, A. K., Breden, F., Alexander, H. J., Chan, W. K., Thakurta, S. G. and Brooks, R., Invasion success and genetic diversity of introduced populations of guppies Poecilia reticulata in Australia. Mol. Ecol., 2005, 14, 3671-3682.

62. Kamath, P. L., Sepulveda, A. J. and Layhee, M., Genetic reconstruction of a bullfrog invasion to elucidate vectors of introduction and secondary spread. Nature Ecol. Evol., 2016, 6, 5221-5233.

63. Hawkins, C. L. et al., Framework and guidelines for implementing the proposed IUCN Environmental Impact Classification for Alien Taxa (EICAT). Divers. Distrib., 2015, 21, 1360-1363.

64. Sen, S., Shivaprakash, K. N., Aravind, N. A., Ravikanth, G. and Dayanandan, S., Ecological niche modeling for conservation planning of an endemic snail in the verge of becoming a pest in cardamom plantations in the Western Ghats biodiversity hotspot Ecol. Evol., 2016, 6, 6510-6523.

65. Lodge, D. M. et al., Risk analysis and bioeconomics of invasive species to inform policy and management. Annu. Rev. Environ. Resour., 2016, 41, 453-488.

66. Adrian-Kalchhauser, I. and Burkhardt-Holm, P., An eDNA assay to monitor a globally invasive fish species from flowing freshwater. PLoS ONE, 2016, 11, e0147558; doi:10.1371/journal. pone. 0147558 .
67. Pocock, M. J., Roy, H. E., Fox, R., Ellis, W. N. and Botham, M., Citizen science and invasive alien species: predicting the detection of the oak processionary moth Thaumetopoea processionea by moth recorders. Biol. Conserv., 2017, 208, 146-154.

68. Bonney, R., Cooper, C. B., Dickinson, J., Kelling, S., Phillips, T., Rosenberg, K. V. and Shirk, J., Citizen science: a developing tool for expanding science knowledge and scientific literacy. BioScience, 2009, 59, 977-984.

69. Lowe, S., Browne, M., Boudjelas, S. and De Poorter, M., 100 of the world's worst invasive alien species: a selection from the global invasive species database. Invasive Species Specialist Group, Auckland, New Zealand, 2000, p. 12.

70. https://www.nies.go.jp/biodiversity/invasive/DB/detail/50230e.html (accessed on 17 July 2019).

71. Sandilyan, S., Invasive alien species of India. National Biodiversity Authority, Chennai, 2018; http://nbaindia.org/uploaded/pdf/ Iaslist.pdf (accessed on 8 December 2019).

72. https://www.thehindu.com/news/cities/Tiruchirapalli/health-deptbegins-breedinggambusia-fish-to-fight-mosquitoes/article29558995.ece (accessed on 19 May 2020).

73. https://timesofindia.indiatimes.com/city/madurai/madurai-corpn-tocombat-denguewith-gambusia-fish/articleshow/70795854.cms (accessed on 19 May 2020).

74. Lundberg, J. G., Kottelat, M., Smith, G. R., Stiassny, M. L. and Gill, A. C., So many fishes, so little time: an overview of recent ichthyological discovery in continental waters. Ann. Miss. Bot. Gard., 2000, 87, 26-62.

Received 11 December 2019; revised accepted 4 September 2020

doi: $10.18520 / \mathrm{cs} / \mathrm{v} 119 / \mathrm{i} 11 / 1752-1759$ 